INVESTIGACIONES

\title{
CONCEPCIONES DEL PROFESOR SOBRE EL USO EDUCATIVO DE LAS TECNOLOGIAS DE LA INFORMACION Y LA COMUNICACION (TIC) ASOCIADAS A PROCESOS DE ENSEÑANZA-APRENDIZAJE EN EL AULA ESCOLAR
}

\author{
Professor's conceptions about the educational use of information \\ and communication technologies in relation to teaching-learning \\ processes in the classroom
}

\author{
Marcelo Arancibia ${ }^{1}$, Carmen Paz Soto ${ }^{2}$, Paulo Contreras ${ }^{3}$ \\ ${ }^{1}$ Universidad Austral de Chile, Instituto de Filosofía y Estudios Educacionales, marceloarancibia@uach.cl \\ ${ }^{2}$ Universidad San Sebastián, sede Valdivia, directora Pedagogía en Historia y Ciencias Sociales, csoto@uss \\ ${ }^{3}$ Universidad Austral de Chile, Instituto de Filosofía y Estudios Educacionales, paulocontreras@uach.cl
}

\section{Resumen}

El propósito de este trabajo es comprender el uso de las Tecnologías de la Información y la Comunicación (en adelante TIC) y su relación con las concepciones sobre enseñanza y aprendizaje de profesores de Historia en la ciudad de Valdivia. Esta investigación se enmarca dentro de un proyecto que cuenta con el patrocinio de la Dirección de Investigación y Desarrollo de la Universidad Austral de Chile (No DID S-200617).

Metodológicamente, se utilizó un modelo cualitativo, con un diseño de investigación correspondiente a Estudio de Casos. Se trabajó con tres profesoras de Historia de la ciudad de Valdivia, utilizando una metodología interpretativa que busca describir, comprender y conocer más profundamente los casos que son objeto de análisis. Los resultados de esta investigación evidenciaron que las categorías construidas teóricamente permitieron caracterizar de manera adecuada las concepciones sobre el uso educativo de las TIC en profesores de Historia, asimismo, en dos casos existe relación entre el discurso y la acción de las profesoras, en tanto el tercer caso muestra inconsistencia.

Palabras clave: concepciones sobre aprender y enseñar, Informática Educativa, Formación de profesores.

\begin{abstract}
This research has as its main purpose understand the use of Information and Communication Technology (ICT), and the relationship between the teacher's conceptions of learning and teaching of history teachers in Valdivia. The investigation is sponsor by the Department of Research and Investigation Development of Universidad Austral de Chile (No DID S-200617).

The methodology approch is cualtitative, following a case study design. The research worked with three history teachers of Valdivia, using an interpretation method, that seeks to describe, understand and get to know deeper the cases that are our subjects of study. The results of this investigation evidence that the categories that were built among a theoretical construction allowed the investigators characterized properly the educational uses of ICT in history teachers, among these we found two cases in which there was a relationship between the speech and the way the used ICT inside the classroom, but the third case showed weakness.
\end{abstract}

Key words: conceptions of learning and teaching, Educational Computer Sciences, Teacher training. 


\section{INTRODUCCION}

La escuela de la sociedad de la información no debe limitarse a ser una mera trasmisora de conocimientos, debe intentar compensar las desigualdades, fomentar el espíritu crítico, la capacidad para procesar y estructurar las informaciones, la imaginación y la inventiva. Para ello, se debe cambiar la concepción de la práctica docente: olvidarse de las currícula cerradas y altamente exigentes, de la "obsesión compulsiva por la estandarización” (Hargraves, 2003: 10), y hacer de la profesión una fuente de ingenio, progreso, para que eventualmente nuestros alumnos(as) sean ciudadanos(as) del mundo. Consecuente con esto se debe olvidar el individualismo y la autonomía personal, convirtiendo a los docentes en comunidades profesionales de aprendizaje y redes virtuales y presenciales, donde los profesores se conviertan en actores fundamentales para liderar este proceso.

Progresivamente las TIC van formando parte del conjunto de recursos disponibles en los centros escolares, promoviendo así la incorporación de los estudiantes al mundo digital. Sin embargo, la integración pedagógica de las TIC en dichos centros, y especialmente en las aulas escolares, a menudo se ha constituido en un proceso complicado, problemático y aún no logrado (Mumtaz, 2000; Arancibia, 2002).

En este contexto se inserta la presente investigación, cuyo propósito es comprender las relaciones entre el uso de las TIC y las concepciones de enseñanza-aprendizaje en profesores de Historia. Específicamente, interesa describir cómo los docentes evidencian en su práctica pedagógica el uso de las TIC en la educación disciplinar, la organización del trabajo en el aula y en la relación que establecen con sus educandos.

Así también, la investigación en este campo reconoce en los profesores un rol fundamental en la renovación educacional contemporánea y, por tanto, también en la incorporación curricular de las TIC (Cabero, 1991; Zhao y Frank, 2003). En estos estudios se atribuye al profesor un papel fundamental para lograr una integración pedagógica de las TIC, poniendo en evidencia que éstos son una de las claves para obstaculizar o favorecer dicha integración en los centros y en las aulas escolares. La interrelación de estas reflexiones pone en evidencia que en la actualidad es necesario profundizar en mayor medida en la investigación educativa los factores relativos al profesor que inciden en la integración pedagógica de las TIC en el aula escolar.

Por último, es necesario advertir que este estudio es novedoso, pues busca la relación entre las TIC y el pensamiento del profesor(a) a partir de la definición de sus concepciones; en este ámbito los estudios son más bien escasos, sobre todo aquellos focalizados particularmente en profesores de Historia. En este artículo pretendemos entregar los resultados que permiten caracterizar las concepciones sobre aprender y enseñar con TIC de tres profesoras de Historia de Enseñanza Media de la comuna de Valdivia y su relación con la práctica de aula.

\section{CONCEPCIONES DEL PROFESOR SOBRE APRENDER Y ENSEÑAR}

Las concepciones son una construcción mental de los sujetos en relación a las experiencias sensibles que tienen con sus contextos. Ahora bien, la definición extraída de Pechorromán y Pozo (2006) establece que la concepción es una construcción epistémica relatada. Esto quiere decir que es verbalizada y construida como categoría global 
epistemológica sobre la realidad. Las otras, en cambio, las sitúan como construcciones erigidas desde la experiencia concreta y cercana: no vienen necesariamente "cargadas" en nuestro inconsciente.

Desde nuestra perspectiva -y adentrándonos en una definición propia- afirmamos el hecho de que cada uno de nosotros poseemos unas maneras de interpretar el mundo que son asumidas (tal vez nunca discutidas), que constituyen toda una gama de procesos y relaciones cognitivas que orientan nuestro actuar; esta configuración epistémica de la cognición tiene su origen en la cultura en la cual el sujeto está inmerso, a partir de un marco que posibilita la construcción de concepciones sobre el mundo, esto es, concepciones respecto de la realidad. Las concepciones, en tal caso, engloban teorías y representaciones, como también creencias y conocimientos: son la fusión de lo que valoramos (creencia) y sabemos (conocimiento) (Pozo, 2006).

Para los propósitos de este trabajo entendemos por concepciones el conjunto de creencias y conocimientos de origen esencialmente cognitivo, de carácter interno, construidas desde nuestra experiencia sensible y que vienen a ser las organizadoras implícitas de los conceptos que orientan nuestras acciones. Así, una concepción denota la naturaleza y el sentido asignado a las acciones y a los objetos (en nuestro caso aprender y enseñar con TIC) y con ello hace referencia a las diferentes construcciones relacionales que se producen en la mente, ya sean simbólicas, gráficas, de sentido u otro tipo. Por tanto, las concepciones aparecen vinculadas a las representaciones cognitivas y a las creencias que los individuos nos formamos de la realidad (Da Ponte, 1999; Thompson, 1992).

Por ejemplo, un profesor construye sus concepciones sobre los fines de la educación según las experiencias profesionales, formativas y de vida. De este modo, podemos encontrar una concepción sobre los fines de la educación de tipo técnico instrumental, es decir, que privilegia en la acción educativa la entrega de contenidos culturales específicos y apropiados a la reproducción. De otro modo, una concepción definida como humanizadora privilegiará acciones didácticas tendientes a fomentar el desarrollo del espíritu y los ejes transversales de valores y actitudes. También es posible configurar una concepción de tipo transformadora, en la cual adscribimos ideas respecto de los fines de la educación como acción social, que tiende a la transformación y el fomento del espíritu crítico.

Este sería el procedimiento mediante el cual los profesores preferentemente conformarían sus concepciones como estructuras de sentido epistémicas de acuerdo a sus experiencias vividas, relacionadas ya sea a sus procesos formativos (escolares y universitarios), a las "escuelas" de pensamiento hegemónicas existentes en sus centros de formación profesional y a sus prácticas profesionales.

Si nos basamos en los paradigmas psicoeducativos, siguiendo la lógica de lo expuesto, es posible de manera preliminar conformar una categorización dicotómica conductista/ constructivista de concepciones sobre aprender y enseñar. No obstante, es necesario advertir, por ahora, que esta dualidad no es pertinente, ya que según observamos en los enfoques constructivistas existen tres líneas que son posibles de identificar con nitidez: constructivismo cognitivo, sociocultural y radical (Coll, 2005). Siguiendo la misma lógica, podemos pensar en una matriz categorial de concepciones sobre aprender y enseñar en cuatro ejes, que consideren las tres corrientes constructivistas más el conductismo. Sin embargo, estamos con Pozo (2006: 126) cuando hace notar que en las corrientes constructivistas el constructivismo radical, o lo que denomina teorías postmodernas, al ser de data más reciente no tiene, al parecer, demasiada influencia en las personas, por tanto 
sería un modelo en ciernes que aún no permite identificar claramente una categoría de concepción sobre aprender y enseñar en sí misma.

Por ello, observamos más bien la configuración de una estructura categorial de concepciones en tres ejes. En primer lugar, una concepción de tipo "transmisionista", que privilegia la entrega de información y un aprendizaje reproductivo por parte de los estudiantes, cercana a una posición "psicoeducativa conductista", que pese a estar obsoleta como teoría psicológica, aún es plausible encontrarla en las concepciones de profesores sobre aprender y enseñar. En segundo lugar, una categoría de tipo "interaccionista" con tendencia a provocar un aprendizaje activo a través de procesos de interacción prediseñados en el aula, alimentado por el constructivismo cognitivo, pues persigue preferentemente realizar acciones de enseñanzas propensas a la asimilización y acomodación cognitiva en la búsqueda de nuevos equilibrios psicológicos traducidos en aprendizaje. En tercer lugar, una concepción de carácter abierto con orientación hacia el logro de la autonomía en el proceso de aprender con prácticas un tanto desestructuradas o bien deconstructivas que tienen como base el constructivismo social y en menor medida elementos del radical: basados en la experiencia humana, como catalizador del aprendizaje, fomenta prácticas asentadas en la disposición de apoyos didácticos (andamiaje) y la configuración de las llamadas "zonas de desarrollo próximo".

Para efectos de nuestro estudio es relevante postular que el conocimiento es el contenido relacional entre lo que se ha de conocer (el objeto) y las elaboraciones cognitivas que estructuran las personas que conocen. Además, un conocimiento asegurado -aprehendido-, resulta estable como resultado de un proceso interno, aunque validado socialmente al ser explicitado, logrando cierto consenso y niveles de comprobación empírica avalados por el grupo o colectivo social de referencia.

Según lo dicho -respecto de la construcción y la naturaleza del conocimiento- surge la posibilidad de homologarla con la configuración preliminar de una estructura categorial de concepciones en tres ejes. En primer lugar, una concepción de tipo reproductiva, donde podemos creer que el conocimiento es un objeto "traspasable", por tanto posible de grabar en las mentes de otros individuos a través de un acto social de transmisión, denominado genéricamente enseñanza, donde las concepciones estarían sustentadas en una realidad externa objetiva. En segundo lugar, una categoría que podríamos denominar de tipo "constructiva", donde el conocimiento es producto de una construcción interna, de naturaleza subjetiva. En tal caso, todo acto de enseñanza debe estar supeditado a las motivaciones y estructuras previas de los sujetos que han de aprender.

\section{APRENDER Y ENSEÑAR CON TIC EN CONTEXTOS ESCOLARES}

Las innovaciones tecnológicas, tales como la radio o la televisión, en toda época han sido utilizadas y adaptadas al sistema educativo constituyéndose en un objeto preferente para la investigación educativa (Cuban, 1986); en la actualidad la irrupción de los ordenadores y de las redes está cambiando claramente el escenario. Existen indicios de que los profesores reconocen el vasto y potencial aporte de las TIC para transformar sus prácticas educativas y -aunque en menor medida- favorecer el aprendizaje de sus estudiantes. Con todo, estas tecnologías nos han obligado a repensar la enseñanza (Hargreaves, 2003; Esteve, 2003; Castells, 1997). 
Respecto de la investigación psicoeducativa sobre la relación aprendizaje/TIC, si bien es abundante en los últimos diez años, no es menos cierto que se ha conducido más bien por ámbitos lejanos a nuestro estudio, básicamente en función de la definición o aclaración de los efectos respecto de cómo afectan en el rendimiento escolar, cómo son organizados los ambientes para aprender con ellas y, en el último lustro, estudios vinculados preferentemente al e-learning, los entornos virtuales, objetos de aprendizaje, la educación virtual a distancia y el trabajo colaborativo mediado por ordenadores; en consecuencia, estudios que ven en las TIC instrumentos mediadores en el proceso de aprender (Crook, 1998; Duart y Sangrà, 2000; Snyder 2004).

Es así como la revisión de estudios sobre TIC y aprendizaje nos conduce a abordar cuestiones de los dos grandes paradigmas psicoeducativos, es así como el enfoque cognitivo difiere, en cuanto al uso de TIC, con aquellos estudios orientados por la aproximación conductista, pues esta persigue preferentemente establecer la efectividad de un recurso o medio informático sobre el rendimiento de los estudiantes, la organización del trabajo en aula y la innovación de las prácticas docentes con propósitos de validar su estructura y su eficacia en cuanto recurso pedagógico. En tanto indagaciones con una fundamentación en los paradigmas cognitivos buscan más bien describir las modificaciones respecto de los aspectos en el comportamiento de los sujetos centrándose en los procesos cognitivos del ser humano y cómo contribuyen las TIC en la conformación de modelos y esquemas mentales. Algunas conclusiones sobre el aprendizaje desde las ciencias cognitivas llevaron a Reggini (1988) a destacar cinco puntos que responden a la manera cómo la computadora debe emplearse en la enseñanza, los que en este tiempo parecen una obviedad pero que, como veremos, no necesariamente son aplicados en las actividades con TIC en contextos educativos, a saber estos puntos fueron: Los alumnos adquieren o elaboran por sí mismos sus conocimientos; el aprendizaje de cualquier tema se apoya en conocimientos anteriores; para aprender algo hay que conocer sus relaciones y derivaciones; el aprendizaje depende de factores no sólo intelectuales, sino efectivos y emocionales, y las personas aprenden haciendo y pensando en lo que hacen.

Encontramos varios trabajos que abordan de manera próxima el tema. Como el de Lefebvre, Deaudelin y Loiselle (2006), quienes indican que existen etapas de incorporación de las TIC, las cuales asociadas a las prácticas y a las concepciones muestran una variabilidad en cuanto a la clasificación de un profesor. Dadas así las cosas, etapas diferentes suponen concepciones diferentes obteniéndose más bien una mezcla o mixtura entre concepciones y usos, pues los profesores se moverán entre sus concepciones y usos de manera indistinta marcados básicamente por su nivel de manejo de las TIC en torno a dos orientaciones o categorías definidas por las autoras como neocontructivista y neoconductista en función de los paradigmas psicoeducativos principales. En este estudio se presentan ocho ámbitos o eventos para observar la práctica con TIC, a saber: secuencia de eventos de la actividad; eventos imprevistos; recursos sociales; recursos temporales; recursos informáticos; tarea a desarrollar; presentación del contenido, y retroalimentación. Como veremos más adelante, esta estructura orienta nuestro registro de observación.

Otro estudio es el de Drenoyianni y Selwood (1998) que trabaja con el concepto de racionalidades para definir los modos de concebir que los profesores tienen sobre sus prácticas con TIC estructurando cuatro: social, caracterizada como aquella que utiliza las TIC para preparar a los estudiantes para el mundo del mañana; vocacional, que preparara para el mundo del trabajo; pedagógica, que usa el computador como asistente de los 
procesos de aprendizaje definidos curricularmente, y catalizadora, definida por una orientación en su uso para la transformación de las prácticas de enseñanza (innovación). Los resultados de este trabajo reflejan dos amplios grupos de profesores: Los que adoptan una perspectiva hacia el conocimiento de la computadora, o sea, vocacional, y los que creen que la computadora se debe utilizar como medio para facilitar y mejorar la enseñanza y aprendizaje, es decir, pedagógico. Además, los resultados revelan una asociación entre las concepciones de los profesores sobre uso de la computadora y las maneras o formas en el uso real que hacen ellos de la computadora en sus clases. También los autores establecen que las innovaciones educativas se concretizan en la práctica del profesor sólo en cuanto se asocian con la manera de pensar de los profesores. Algunos de los aspectos que fueron considerados de este estudio para establecer las relaciones entre concepciones y prácticas con TIC, fueron la claridad con que hay que identificar aspectos personales de los profesores y sus características formativas individuales y sobre metas educativas; la frecuencia con que utilizan el computador y cómo planifican con TIC; las decisiones de los profesores antes de tales actividades y su papel durante el trabajo; las interacciones ante la computadora, y los cambios (mejoras) educativos globales percibidos por ellos luego del trabajo con TIC; los problemas a que se ven enfrentados para diseñar la enseñanza con computadoras, así como también respecto de las dificultades cuando las usan; por último, el tipo de perfeccionamiento especializado en TIC recibido y cuáles son sus peticiones para futuras experiencias de formación.

Un tercer estudio es el de Niederhauser y Stoddart (2001), quienes presentan el hallazgo entre las "perspectivas instruccionales" de los profesores respecto del uso de software educativo de un paradigma denominado didáctico (Niederhauser y Stoddart 2001), caracterizado por presentar un enfoque más bien pragmático de uso del computador de maneras diversas orientándolo a resolver problemas de la práctica de enseñanza y del aprendizaje estudiantil. Así, a paradigmas opuestos (transmisionista/contructivista) propuestos a priori en el estudio emerge desde la misma práctica uno que obedece a criterios pragmáticos o instrumentales que permite dar respuesta a los problemas cotidianos y que es definido como didáctico.

En el estudio desarrollaremos una categorización que recoge en parte la tríada categorial configurada por el enfoque de las teorías implícitas expuesto en el texto de Pozo et al. (2006), toda vez que establece relación entre concepciones del profesor sobre enseñar y aprender con las diferentes tradiciones psicoeducativas vigentes; estas categorías las fusionamos y adaptamos con las dimensiones que nos proponen Lefebvre, Deaudelin y Loiselle (2006) y Drenoyianni y Selwood (1998) y que expresamos como queda en las categorías y dimensiones definidas en la tabla 2.

Al basarnos en estos enfoques establecemos que existen concepciones de orden teórico estructuradas como teorías epistémicas (implícitas), en este caso sobre aprender y enseñar, pero que al mismo tiempo estas teorías son expresadas de diferentes maneras según la disciplina y los contextos específicos de desempeño profesional de los profesores. En tal caso, los profesores configuran sus concepciones de manera consecuente con su sistema de valores y teorías relacionados con su disciplina y la escuela. Por ello una determinada concepción tiene un arraigo en sus experiencias de formación como de trabajo profesional.

Esta mirada nos lleva a elaborar categorías sobre aprender y enseñar necesariamente vinculadas, en nuestro caso Historia. De allí que las categorías construidas sobre aprender 
y enseñar serán propias a los procesos de enseñanza y aprendizaje de la disciplina en contexto escolar.

Asimismo, nuestra postura establece que las concepciones de los profesores están relacionadas tanto con las decisiones que adoptan, como con las acciones que realizan, antes, durante y después de sus prácticas educativas.

Asumimos igualmente la perspectiva que ve necesario estudiar de manera integrada las concepciones sobre aprender y enseñar, puesto que se ha comprobado, de manera efectiva, que cuando las conceptualizaciones de los profesores sobre enseñanza y aprendizaje fueron estudiadas por separado y sometidas más adelante a los análisis para determinar el grado de coincidencia, no fue posible encontrar diferencias significativas entre ambas (Boulton-Lewis et al., 2001). Por ello, en este estudio entendemos la enseñanza y el aprendizaje como dos procesos interrelacionados e inseparables.

\section{METODOLOGIA DE LA INVESTIGACION}

El trabajo de investigación sigue un modelo analítico basado en casos. Se utiliza una metodología interpretativa que busca conocer y comprender en profundidad los casos que son objeto de análisis. Stake (1999: 16) define el caso como algo específico, complejo y en funcionamiento. A su vez estos estudios son definidos por Sandin (2003) como un tipo de investigación caracterizado por un análisis detallado, comprensivo y minucioso del caso que manifiesta el objeto del estudio. En tal sentido, es un trabajo particularista, descriptivo, heurístico, inductivo y cooperativo en términos de la relación de los actores involucrados y el investigador propiamente tal. El investigador observa las características de una unidad individual -en este caso una Unidad Didáctica- y el modo cómo las profesoras de Historia utilizan las TIC. De esta forma, observar cómo se relacionan sus prácticas con sus concepciones sobre enseñanza y aprendizaje.

\subsection{SELECCION DE LOS CASOS}

Para efectos de nuestra investigación en la selección de los casos, y atendiendo a las consideraciones de Stake (1999: 17), se utilizará como criterio principal la voluntariedad, lo que nos lleva a actuar bajo procedimientos teóricos, puesto que al ser limitada la población (docentes de Historia de Enseñanza Media que usen TIC en la ciudad de Valdivia) se debió contactar a maestros conocidos o bien referidos. En síntesis, los criterios teóricos utilizados para escoger los casos fueron:

a) Profesoras de Historia que trabajan en la Enseñanza Media en diferentes establecimientos educacionales y que utilizan en algún grado las TIC en sus prácticas docentes.

b) Voluntad de Participación de los Docentes en el Estudio: Este criterio es el de mayor relevancia, pues marca la disponibilidad casi absoluta de los docentes para participar dentro de la investigación y el compromiso de enfrentar todas las tareas o diligencias que de ella se desprendan.

c) Disponibilidad Institucional: La selección de estos casos también estuvo subordinada a la factibilidad de la investigación en los establecimientos en los cuales las docentes se desempeñan. 


\subsection{DESCRIPCION DE LOS CASOS}

Los aspectos personales y contextuales de los tres casos seleccionados son presentados en la siguiente tabla:

\section{Tabla 1}

Descripción de Casos

\begin{tabular}{|c|c|c|c|}
\hline Característica & Caso 1 & Caso 2 & Caso 3 \\
\hline Tipo colegio & Particular & $\begin{array}{c}\text { Particular } \\
\text { Subvencionado }\end{array}$ & $\begin{array}{c}\text { Particular } \\
\text { Subvencionado }\end{array}$ \\
\hline Edad & 41 & 35 & 30 \\
\hline Formación & $\begin{array}{c}\text { Profesora de } \\
\text { Historia y } \\
\text { Geografía y } \\
\text { Educación Cívica }\end{array}$ & $\begin{array}{c}\text { Profesora de } \\
\text { Historia y } \\
\text { Geografía }\end{array}$ & $\begin{array}{l}\text { Profesora de } \\
\text { Historia y } \\
\text { Geografía }\end{array}$ \\
\hline Institución Formadora & $\begin{array}{l}\text { Universidad Austral } \\
\text { de Chile }\end{array}$ & $\begin{array}{l}\text { Universidad } \\
\text { Católica de } \\
\text { Valparaíso }\end{array}$ & $\begin{array}{c}\text { Universidad de Los } \\
\text { Lagos }\end{array}$ \\
\hline Formación permanente & $\begin{array}{l}\text { Cursa magíster en } \\
\text { Ciencias Sociales } \\
\text { Universidad Arcis }\end{array}$ & $\begin{array}{c}\text { Cursó magíster } \\
\text { en Informática } \\
\text { Educativa en la } \\
\text { Universidad de la } \\
\text { Frontera }\end{array}$ & \\
\hline Nivel de aplicación & $\begin{array}{c}\text { Cuarto año de } \\
\text { Enseñanza Media }\end{array}$ & $\begin{array}{c}\text { Tercer año de } \\
\text { Enseñanza Media }\end{array}$ & $\begin{array}{c}\text { Cuarto año de } \\
\text { Enseñanza Media }\end{array}$ \\
\hline Unidad Didáctica & $\begin{array}{l}\text { Primera Guerra } \\
\text { Mundial }\end{array}$ & $\begin{array}{l}\text { Mundo Antiguo } \\
\text { Grecia y Roma }\end{array}$ & $\begin{array}{l}\text { Guerra Fría y } \\
\text { Descolonización }\end{array}$ \\
\hline Años de experiencia & 17 años & 8 años & 6 años \\
\hline $\begin{array}{l}\text { Años de experiencia } \\
\text { en colegio }\end{array}$ & 15 años & 5 años & 6 meses \\
\hline
\end{tabular}

Fuente: Propia.

\subsection{TECNICAS DE RECOLECCION DE DATOS}

\section{a) Entrevista Semiestructurada}

La entrevista semiestructurada pretende comprender más que explicar, busca maximizar el significado, dar con la respuesta subjetivamente sincera. Obtiene con frecuencia respuesta emocional, pasando por alto la racionalidad (Ruiz Olabuénaga, 1999: 170). Tienen una secuencia de temas y algunas preguntas generadoras. 
Los focos de esta entrevista se circunscriben a aspectos relacionados con:

- Datos personales y características profesionales del entrevistado.

- Caracterización sobre aprendizaje y enseñanza de la historia: Concepción epistemológica, formación y actualización, aprendizaje, planificación, acción didáctica, evaluación.

- Caracterización de las concepciones sobre aprender y enseñar con TIC: Manejo de éstas, formación en TIC, funciones asignadas a ellas, utilidad, labores en las que las utiliza.

\section{b) Registro de campo}

La observación participante depende del registro de notas de campo, las que deben ser completas, precisas y detalladas, no deben incluir sólo descripciones de lo que ocurre, sino también un registro de los sentimientos, interpretaciones (Taylor y Bodgan, 2002).

En este caso el registro de campo fue estructurado de la siguiente manera:

- Datos institucionales.

- Antecedentes del curso.

- Diagrama de aula.

- Actividades por segmentos y comentarios.

- Observaciones.

\section{c) Cuadro de códigos y categorías}

A partir del marco teórico de esta investigación se creó un cuadro con códigos y categorías que será el instrumento con el cual será analizada la investigación. Este cuadro responde a los tres tipos de profesores que se caracterizan: uno transmisionista-reproductivo, uno interaccionista-constructivo y por último uno abierto-autónomo. Para cada uno de ellos hay descriptores que los definen (ver tabla 2).

\subsection{TIPO DE ANALISIS}

Esta investigación, siguiendo a Strauss y Corbin (2002), aborda el análisis a partir de la codificación abierta, que entiende el proceso analítico por medio del cual se identifican los conceptos y se descubren en los datos sus propiedades y dimensiones, y de la codificación la codificación axial, que es un proceso de relacionar las categorías a sus subcategorías, denominada así porque la codificación ocurre alrededor del eje de una categoría, y enlaza las categorías en cuanto a sus propiedades y dimensiones. Este proceso no se realiza en forma lineal ni mecánica, se analiza una y otra vez esta conceptualización hasta organizar estos conceptos en categorías más abstractas para distinguir en ellas propiedades y dimensiones particulares y específicas, que se traduce en este caso en la construcción de la matriz de análisis (ver tabla 2).

La codificación fue hecha de manera diferente; en el discurso se trabajó con las citas textuales de las profesoras, en cambio; con los registros audiovisuales son segmentos de su práctica pedagógica con el uso de TIC la que es codificada. En esta segmentación, que es encriptada, se evidencian las concepciones de las docentes; es así como también 
las encontramos en su discurso. Por último, ambas codificaciones fueron hechas con la anterior matriz de análisis. Esta codificación consistió en adosar códigos a segmentos de textos (las transcripciones realizas o bien los registros audiovisuales) identificando y diferenciando así, unidades de significado. El proceso de codificación también comprendió la recodificación y la agrupación de códigos (Vasilachis, 2006: 252). Para trabajar con estos códigos se utiliza el software para análisis Atlas Ti.

\section{Tabla 2}

Matriz de Familias y códigos para análisis de videos y discursos

\begin{tabular}{|c|c|c|c|}
\hline \multirow[b]{2}{*}{ Dimensión } & \multicolumn{3}{|c|}{ Categoría/Códigos } \\
\hline & $\begin{array}{l}\text { Transmisionista/ } \\
\text { Reproductiva }\end{array}$ & $\begin{array}{c}\text { Interaccionista/ } \\
\text { Constructiva }\end{array}$ & $\begin{array}{l}\text { Abierta/ } \\
\text { Autónoma }\end{array}$ \\
\hline $\begin{array}{l}\text { Roles de la } \\
\text { profesora }\end{array}$ & $\begin{array}{l}\text { Expositor } \\
\mathbf{t 1}\end{array}$ & $\begin{array}{c}\text { Tutor } \\
\text { i1 }\end{array}$ & $\begin{array}{c}\text { Guía y orientador } \\
\text { a1 }\end{array}$ \\
\hline $\begin{array}{l}\text { Roles del } \\
\text { discente }\end{array}$ & $\begin{array}{l}\text { Estudiar, seguir } \\
\text { instrucciones } \\
\mathbf{t} \mathbf{2}\end{array}$ & $\begin{array}{l}\text { Activo dentro de un marco } \\
\text { previamente definido } \\
\text { i2 }\end{array}$ & $\begin{array}{l}\text { Proactivo y autónomo } \\
\qquad \mathbf{a} 2\end{array}$ \\
\hline $\begin{array}{l}\text { Fines } \\
\text { Educativos }\end{array}$ & $\begin{array}{l}\text { Definidos por el } \\
\text { currículum pre-escrito } \\
\text { t3 }\end{array}$ & $\begin{array}{c}\text { Adscritos a la cultura } \\
\text { escolar } \\
\text { i3 }\end{array}$ & $\begin{array}{l}\text { Un acto de liberación y } \\
\text { de crecimiento personal } \\
\text { a3 }\end{array}$ \\
\hline $\begin{array}{l}\text { Formación } \\
\text { permanente y } \\
\text { actualización }\end{array}$ & $\begin{array}{c}\text { En la disciplina } \\
\mathbf{t 4}\end{array}$ & $\begin{array}{l}\text { Técnicas y recursos } \\
\text { didácticos } \\
\text { i4 }\end{array}$ & $\begin{array}{c}\text { Adaptar la enseñanza a } \\
\text { los conocimientos y las } \\
\text { capacidades previos } \\
\text { a4 }\end{array}$ \\
\hline $\begin{array}{l}\text { Organización } \\
\text { del trabajo } \\
\text { en el aula }\end{array}$ & $\begin{array}{l}\text { Variado, prioriza el } \\
\text { trabajo efectivo } \\
\text { t5 }\end{array}$ & $\begin{array}{l}\text { Privilegia la configuración } \\
\text { de diversos ambientes } \\
\text { i5 }\end{array}$ & $\begin{array}{c}\text { Negociado y emergente } \\
\mathbf{a 5}\end{array}$ \\
\hline $\begin{array}{l}\text { Contextualización } \\
\text { del aprendizaje }\end{array}$ & $\begin{array}{c}\text { Limitado a la entrega } \\
\text { de ejemplos } \\
\text { t6 }\end{array}$ & $\begin{array}{c}\text { Motivar al estudiante con } \\
\text { el contenido del curriculo } \\
\text { i6 }\end{array}$ & $\begin{array}{l}\text { Sustento base de la } \\
\text { enseñanza (ZDP) } \\
\mathbf{a 6}\end{array}$ \\
\hline Uso de TIC & $\begin{array}{c}\text { Fuentes de información } \\
\text { alternativas. } \\
\text { t7 }\end{array}$ & $\begin{array}{c}\text { Complemento y apoyo a } \\
\text { su labor } \\
\text { i7 }\end{array}$ & $\begin{array}{c}\text { Libertad para su uso por } \\
\text { parte de los estudiantes } \\
\text { a7 }\end{array}$ \\
\hline Evaluación & $\begin{array}{c}\text { Rutinaria, estructurada } \\
\text { y objetiva, orientada } \\
\text { a los resultados y la } \\
\text { calificación } \\
\text { t8 }\end{array}$ & $\begin{array}{c}\text { Utiliza diferentes } \\
\text { instrumentos, le interesa el } \\
\text { proceso, el resultado y las } \\
\text { calificaciones } \\
\text { i8 }\end{array}$ & $\begin{array}{c}\text { Procedimientos auténticos } \\
\text { y abiertos orientados a } \\
\text { los procesos y al auto } \\
\text { reporte } \\
\text { a8 }\end{array}$ \\
\hline $\begin{array}{l}\text { Relevancia } \\
\text { de aprender } \\
\text { historia }\end{array}$ & $\begin{array}{l}\text { Formar ciudadanos } \\
\text { que conozcan los } \\
\text { principales hitos de la } \\
\text { historia como personas } \\
\text { cultas y responsables } \\
\mathbf{t 9}\end{array}$ & $\begin{array}{l}\text { Un medio que ayuda a } \\
\text { comprender los fenómenos } \\
\text { de la vida cotidiana } \\
\text { i9 }\end{array}$ & $\begin{array}{c}\text { Configuración de } \\
\text { miradas críticas y } \\
\text { posicionamientos propios } \\
\mathbf{a 9}\end{array}$ \\
\hline
\end{tabular}




\begin{tabular}{|c|c|c|c|}
\hline \multirow[b]{2}{*}{ Dimensión } & \multicolumn{3}{|c|}{ Categoría/Códigos } \\
\hline & $\begin{array}{l}\text { Transmisionista/ } \\
\text { Reproductiva }\end{array}$ & $\begin{array}{l}\text { Interaccionista/ } \\
\text { Constructiva }\end{array}$ & $\begin{array}{l}\text { Abierta/ } \\
\text { Autónoma }\end{array}$ \\
\hline $\begin{array}{l}\text { Racionalidad en } \\
\text { el uso de TIC }\end{array}$ & $\begin{array}{l}\text { Vocacional y social } \\
\text { t10 }\end{array}$ & $\begin{array}{c}\text { Social y pedagógica } \\
\text { i10 }\end{array}$ & $\begin{array}{c}\text { Catalizadora } \\
\text { a10 }\end{array}$ \\
\hline $\begin{array}{l}\text { Tipo de ayuda } \\
\text { que ofrece a sus } \\
\text { estudiantes y su } \\
\text { papel durante el } \\
\text { trabajo }\end{array}$ & $\begin{array}{l}\text { Soluciones tecnológicas, } \\
\text { da las instrucciones } \\
\text { y supervisa el } \\
\text { cumplimiento de las } \\
\text { tareas } \\
\text { t11 }\end{array}$ & $\begin{array}{l}\text { Apoyo tecnológico y } \\
\text { respuestas sobre las } \\
\text { actividades. } \\
\text { Deja que los alumnos } \\
\text { trabajen } \\
\text { i11 }\end{array}$ & $\begin{array}{c}\text { Guía el conflicto } \\
\text { cognitivo } \\
\text { Se involucra en las } \\
\text { actividades como uno } \\
\text { más } \\
\text { a11 }\end{array}$ \\
\hline $\begin{array}{l}\text { Frecuencia } \\
\text { de uso de los } \\
\text { computadores }\end{array}$ & $\begin{array}{l}\text { Permite su uso pero } \\
\text { prefiere no trabajar } \\
\text { directamente con } \\
\text { ordenadores en su clase } \\
\text { t12 }\end{array}$ & $\begin{array}{l}\text { Esporádica. Los usa sólo } \\
\text { cuando es estrictamente } \\
\text { necesario y porque es una } \\
\text { exigencia social. } \\
\text { i12 }\end{array}$ & $\begin{array}{l}\text { Habitual, los considera } \\
\text { relevantes por su relación } \\
\text { con el contexto de los } \\
\text { estudiantes } \\
\mathbf{a 1 2}\end{array}$ \\
\hline $\begin{array}{l}\text { El tipo de } \\
\text { software que } \\
\text { utilizan según } \\
\text { los temas del } \\
\text { plan de estudios }\end{array}$ & $\begin{array}{c}\text { Software de } \\
\text { productividad, software } \\
\text { cerrados, enciclopedias } \\
\text { y Web previamente } \\
\text { indicadas } \\
\mathbf{t 1 3}\end{array}$ & $\begin{array}{l}\text { Software de productividad, } \\
\text { software cerrados, } \\
\text { enciclopedias y búsqueda } \\
\text { de Web } \\
\text { i13 }\end{array}$ & $\begin{array}{l}\text { Software de productividad, } \\
\text { software cerrados y } \\
\text { abiertos, enciclopedias y } \\
\text { búsqueda de Web, todas } \\
\text { las potenciales } \\
\text { herramientas de Internet } \\
\text { a13 }\end{array}$ \\
\hline $\begin{array}{l}\text { Las interacciones } \\
\text { ante la } \\
\text { computadora }\end{array}$ & $\begin{array}{c}\text { Alumno - ordenador } \\
\mathbf{t 1 4}\end{array}$ & $\begin{array}{c}\text { Alumno - ordenador } \\
\text { Alumno - profesor } \\
\text { i14 }\end{array}$ & $\begin{array}{c}\text { Alumno - ordenador } \\
\text { Alumno - profesor } \\
\text { Alumno - alumno } \\
\text { Profesor - ordenador } \\
\text { a14 }\end{array}$ \\
\hline
\end{tabular}

\subsection{CRITERIOS DE RIGOR CIENTIFICO}

\section{a) Validez}

Para dar validez al procedimiento la entrevista semiestructurada fue sometida al juicio de expertos. El juicio de expertos es un conjunto de opiniones que pueden brindar profesionales expertos en una disciplina relacionada al proyecto que se está ejecutando. En este caso la entrevista fue revisada por cinco académicos, dos investigadores expertos en métodos cualitativos, una experta en metodología y dos profesores de Historia, los cuales hicieron sus aportes y completaron un protocolo de validación, para finalmente llegar al instrumento que fue aplicado.

\section{b) Triangulación}

La triangulación es un tipo de control de calidad que debiera ser aplicada a todo tipo de investigación cualitativa. Según los autores (Stake, 1999; Ruiz Olabuénaga, 1999) existen distintos tipos de triangulación; para esta investigación se escogió la triangulación de datos o fuentes, donde se utiliza una variedad de datos de diversas fuentes. Se hizo 
una triangulación de primer orden intracasos, utilizando la entrevista semiestructurada, el análisis de la unidad didáctica y el marco teórico de la investigación y una triangulación de segundo orden intercasos.

\section{c) Revisión de los interesados}

En los estudios de caso, los actores desempeñan un papel fundamental, ya que son ellos el objeto del estudio. En el proceso llamado revisión de los interesados se solicita a los actores -en este caso a las profesoras- que examinen sus entrevistas transcritas. Se les pide realizar esto para resguardar la exactitud y la adecuación del material. Se les puede solicitar feedback, sobre su material (Stake, 1999). Esta investigación mostró las transcripciones de sus entrevistas semiestructuradas a las docentes que participaron del estudio y el análisis de las filmaciones digitalizadas. Este ejercicio puede no ser sólo un criterio de rigor científico, sino que además posibilita la reflexión de las profesoras sobre su propia práctica pedagógica.

\section{RESULTADOS}

Al ser un estudio adscrito al paradigma cualitativo, es inevitable contextualizar el fenómeno estudiado, caracterizarlo, describirlo más allá; para esto hemos escogido esta síntesis que recoge esas diferencias de contexto que inciden en las experiencias de las profesoras, y por tanto en sus prácticas. Se mueven dentro de contextos educativos muy diversos, específicos para cada una de ellas, esto siguiendo la perspectiva teórica asumida tiene relación con sus concepciones y por ende con su práctica pedagógica.

El primer caso de estudio se desarrolló en un colegio particular pagado, por tanto el trabajo se realizó con alumnos de un contexto social más bien privilegiado. La profesora contaba con una amplia experiencia de aula. La maestra establece con sus estudiantes relaciones bastante cordiales, y de mucho respeto. El trabajo en el laboratorio de computación lo hizo en un cuarto medio que tenía 30 alumnos, 16 mujeres y 14 hombres. Durante el desarrollo de la unidad didáctica cada uno de los estudiantes contó con un computador.

La segunda profesora trabajaba en colegio particular subvencionado, un colegio de características diferentes al anterior con grupos curso que no superan los 15 estudiantes. La profesora realizó su clase con un tercero medio; el curso, siguiendo la tónica del colegio, era más bien pequeño, siete alumnos, tres mujeres y cuatro hombres. En la sala de computación sólo había tres computadores. La docente prestaba su propio notebook para que sus estudiantes trabajaran, por tanto se trabajaba en grupos. La relación de la docente con sus estudiantes es muy cercana, se evidenció mucho afecto por parte de la maestra con los alumnos y alumnas.

La tercera profesora trabajaba en un colegio particular subvencionado también, pero de alta vulnerabilidad. El curso donde se realizó la unidad didáctica estaba constituido por nueve hombres y tres niñas. La sala de computación tenía 16 equipos, pero no todos funcionaban. Por tanto, los alumnos trabajaron en grupo también, dos frente a un ordenador. La profesora es la más joven de los tres casos, y la con menor experiencia laboral. Ella se plantea muy rígida delante de sus estudiantes. 
En esos contextos educativos diversos se movieron nuestras tres docentes, y los contextos son importantes para implementar prácticas pedagógicas, pero era importante explicitarlo antes de comenzar el análisis más técnico de los casos.

A continuación se procederá a analizar los casos, primero por separado y luego una síntesis comparativa. Cada caso se analizará en el siguiente orden: análisis tabla de frecuencia, análisis mapa axial y por último los eventos significativos del discurso.

\subsection{CASO 1}

a) Análisis tabla de frecuencia caso 1

Tabla 3

Distribución de Frecuencias de Documentos Primarios Caso 1

\begin{tabular}{|c|c|c|c|c|c|}
\hline Códigos & Entrevista & Filmación 1 & Filmación 2 & Reflexión & Total \\
\hline $\mathrm{t} 1$ & 6 & 7 & 1 & 4 & 18 \\
\hline $\mathrm{t} 2$ & 3 & 4 & 0 & 5 & 12 \\
\hline $\mathrm{t} 3$ & 3 & 0 & 0 & 3 & 6 \\
\hline $\mathrm{t} 4$ & 4 & 0 & 0 & 0 & 4 \\
\hline $\mathrm{t} 5$ & 3 & 1 & 0 & 3 & 7 \\
\hline $\mathrm{t} 6$ & 4 & 3 & 1 & 5 & 13 \\
\hline $\mathrm{t} 7$ & 2 & 1 & 1 & 1 & 5 \\
\hline $\mathrm{t} 8$ & 7 & 0 & 0 & 0 & 7 \\
\hline $\mathrm{t} 9$ & 1 & 0 & 0 & 0 & 1 \\
\hline $\mathrm{t} 10$ & 1 & 0 & 0 & 1 & 2 \\
\hline $\mathrm{t} 11$ & 0 & 5 & 1 & 0 & 6 \\
\hline $\mathrm{t} 12$ & 1 & 0 & 0 & 6 & 7 \\
\hline $\mathrm{t} 13$ & 1 & 4 & 2 & 5 & 12 \\
\hline $\mathrm{t} 14$ & 0 & 3 & 2 & 0 & 5 \\
\hline $\mathrm{i} 8$ & 2 & 0 & 0 & 0 & 2 \\
\hline $\mathrm{i} 10$ & 3 & 0 & 0 & 2 & 5 \\
\hline $\mathrm{i} 12$ & 1 & 0 & 0 & 0 & 1 \\
\hline $\mathrm{i} 13$ & 0 & 0 & 0 & 2 & 2 \\
\hline Totales & $\mathbf{4 2}$ & $\mathbf{2 8}$ & $\mathbf{8}$ & $\mathbf{3 7}$ & $\mathbf{1 1 5}$ \\
\hline & & & & & \\
\hline
\end{tabular}

En una visión general la tabla 1 muestra que la totalidad de los códigos anclados en diversas dimensiones de la matriz alcanzan una frecuencia de 115. De este total, la mayor recurrencia corresponde a los códigos t, que corresponde a la categoría 
Transmisionista/Reproductiva. El anclaje ahí fue de 105, dicho anclaje es destacable pues se encuentra presente dentro de todos los documentos primarios de la docente, es decir, es congruente su discurso con su accionar dentro del aula. Esto es coherente con lo que plantea Clark y Peterson (1990), sobre que existen orientaciones básicas de los profesores que estarían dadas por sus pensamientos y las decisiones para poner el currículo en acción.

La primera recurrencia está en el código $t 1$ expositor, que corresponde a la dimensión rol del profesor(a), con 18 anclajes; es destacable que se presente en todos los documentos primarios de la docente. El carácter de expositora prima en ella, destaca que la práctica se ve reflejada en el discurso y viceversa. En este sentido y siguiendo esta lógica su práctica es congruente con su concepciones; siguiendo a Lefebvre, Deaudelin y Loiselle (2006) sus concepciones como una estructura individual cognitiva están en conexión con su ambiente y con su accionar. La segunda recurrencia, 13 códigos, la encontramos en la dimensión, contextualización del aprendizaje, y se refiere a: Limitado a ejemplos $t 6$, también podemos destacar que se presenta en todos los documentos, lo que nos vuelve a hablar de lo consecuente del discurso con el accionar. Podemos destacar también los códigos $t 2$ y $t 14$, en las categorías: Rol del discente e Interacciones con la computadora, respectivamente con 12 .

Nos parece significativo, siguiendo a Moriadellos (1999), que nos muestra que uno de los tipos de profesores que enseña historia está orientado a formar buenos ciudadanos. Esto queda de manifiesto en esta docente, que se adscribe en la dimensión: Relevancia de estudiar historia al código $t 9$. Formar ciudadanos que conozcan los principales hitos de la historia como personas cultas y responsables.

Ahora bien, existe un grado menor de anclaje de códigos i, que corresponden a la categoría Interaccionista/Constructiva, mas el anclaje en esta categoría solamente está presente en el discurso de la profesora y no se aprecia en su práctica pedagógica, por tanto no está en las filmaciones digitalizadas. Los códigos relacionados son $i 8, i 10$, $i 12$, i13. Esto puede ser interpretado como un grado de inconsistencia entre su práctica pedagógica y el discurso, pero por la presencia cuantitativa menor (10 anclajes) y sólo su aparición en la entrevista no es considerado relevante.

Dado este análisis la profesora responde al modelo preferentemente Transmisionista/ Reproductivo, ya que sólo en esa categoría el anclaje es de 105 códigos de 115; ahora bien, la mayoría de ellos pueden ser observados en el documento 1 y en el documento 4, con una recurrencia de 71 códigos. En ambas filmaciones encontramos 36 códigos de esta categoría. Llama la atención lo consecuente del discurso de la profesora con una práctica pedagógica con el uso de TIC, que más bien es utilizada como un recurso más, una de tantas fuentes para el trabajo. Sus interacciones con las TIC no son significativas, su uso es más bien como pizarra; las TIC son vistas como herramientas que sirven para realizar un producto específico, un documento en Word o una presentación power point para exponer un trabajo. En este caso particular las TIC son usadas por la profesora y el estudiante como pizarrón o libro de texto digital. Esto queda claro en la observación de su práctica en aula, y se condice con la recurrencia de seis veces cada uno de los códigos $t 11$ y $t 13$, en los registros audiovisuales. 
b) Análisis mapa axial caso 1

Figura 1

Mapa axial caso 1

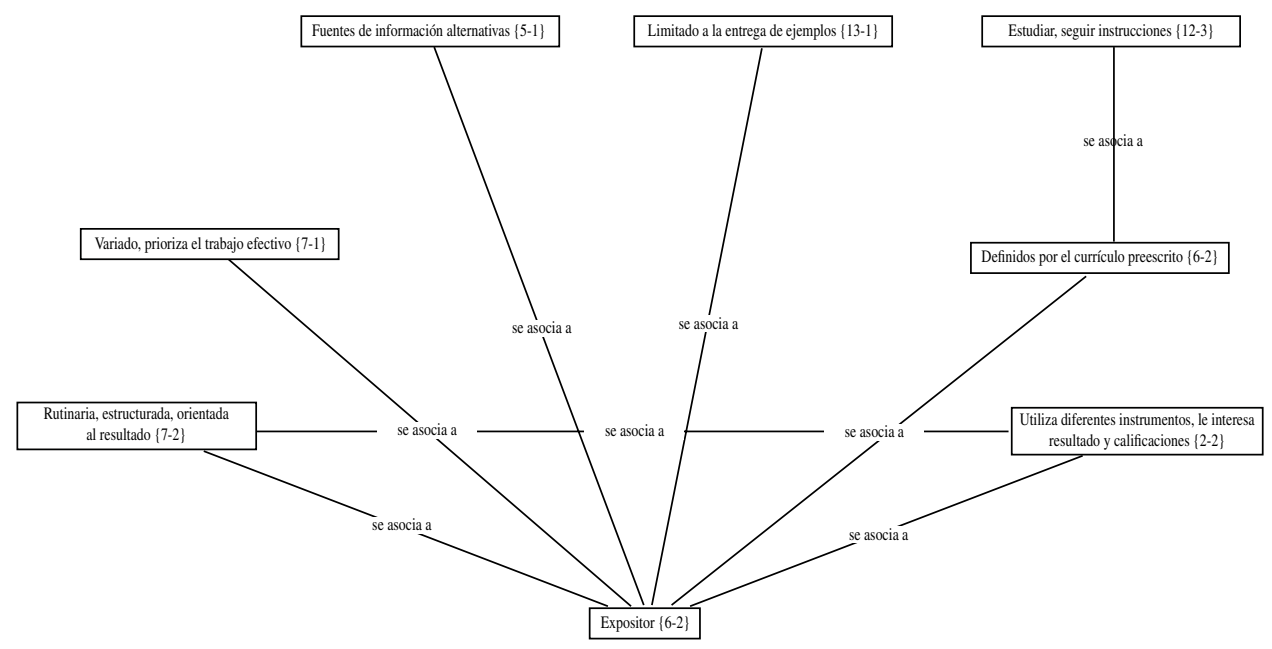

El mapa axial del caso 1 nos muestra un anclaje desde el código $t 1$, de la dimensión rol de la profesora como expositora. También el análisis nos permite observar que este código es el que posee la mayor densidad relacional (18-6), con seis asociaciones, se relaciona con otros códigos: Definidos por el currículum prescrito $t 3$, limitado a la entrega de ejemplos $t 6$, fuentes de información alternativa $t 7$, variado, prioriza el trabajo efectivo $t 5$, rutinaria, estructurada y objetiva, orientada a los resultados y la calificación $t 8$ y por último utiliza diferentes instrumentos, le interesa el proceso, el resultado y las calificaciones $i 7$. Estos dos códigos de una misma dimensión encuentran relación entre sí.

En un segundo nivel de análisis, podemos identificar que de las seis densidades relacionales asociadas al código expositor $t 1$ presenta asociatividad sólo el código: Definidos por el currículo $t 3$, con densidad de dos, su asociación está dada con la dimensión: Rol del discente, que para este caso estaría caracterizado por el código: Estudiar y seguir instrucciones $t 2$.

En consistencia con la tabla de recurrencia en el mapa axial los códigos de mayor recurrencia siguen estando dentro de la categoría Transmisionista/Reproductiva. Es por esto que podemos volver a afirmar que la docente se mueve preferentemente dentro de este tipo de categoría de maestro. Con respecto al uso que hace de las TIC, si bien no se encuentra anclado en el axial, nos haremos cargo de sus análisis a través de los datos textuales, así como también a través de sus citas podremos reforzar su carácter Transmisionista/reproductor. 


\section{c) Eventos significativos del discurso caso 1}

Para hacer el análisis más consistente mostraremos frases del discurso, utilizando los siguientes dispositivos: Tipo de práctica/contextualización de aprendizajes, rol de estudiante y relación con las TIC.

En su entrevista y su reflexión sobre su práctica, la profesora plantea elementos propios de la categoría Transmisionista, donde fundamental es el dominio absoluto de la disciplina por parte del docente. Es fundamental que sean los profesores los que manejen el contenido de manera cabal, sin errores, ni vacíos. Esto muchas veces en desmedro de la didáctica, a nuestro entender fundamental para los aprendizajes de los estudiantes, que requieren significar, resignificar, construir y reconstruir, para así ir aprendiendo.

\section{Citas Textuales}

- ....ser capaz de dar respuestas que demuestren, más que respuestas, perdón, tener una actitud que demuestre dominio...Eso en cuanto a la disciplina.

- Que no te pillen ni por el norte ni por el sur ni por ningún lado.

- La clase debe estar basada en el contenido

Los aprendizajes en su caso los contextualiza limitándose a la entrega de ejemplos, para esto utiliza distintos tipos de fuentes. Las que son necesarias para cumplir con el objetivo de demostrar lo que se está enseñando:

\section{Citas Textuales}

- Por ejemplo a mí me gusta mucho el análisis documental y yo lo uso bastante.

- Ellos pueden ver directamente el sistema de alianzas, ahí las páginas te van mostrando los sistemas de alianzas con flechitas etc., entonces, claro, a ellos les queda tremendamente claro.

En cuanto al rol de sus estudiantes, son éstos los que la miran y a través de esto aprenden. Por tanto, ahí también queda medianamente clara su categorización al identificar el rol de alumno, aquel que sigue instrucciones, aquel que escucha al profesor:

\section{Citas Textuales}

- Esto se hace en la hora de clase, tenemos tanto tiempo pero vamos a usar también trabajo, trabajo personal, pero ellos no, en el fondo no habían avanzado en lo que tenían que hacer en la casa y eso implicó ir nuevamente; si ustedes se dan cuenta estoy en lo mismo, no he avanzado, no he salido grandemente de los antecedentes, etc. Porque ellos no habían hecho lo que tenían que hacer.

Para terminar analizaremos la interacción de esta categoría de profesora con las TIC, donde su uso es también congruente con la categoría a la cual se adscribe principalmente. Le complica entrar al laboratorio multimedial, siente que la dependencia de los alumnos con ella se pierde si ellos son los que utilizan el ordenador, incluso le parece que se le desordenan. Por tanto, prefiere utilizar TIC más bien de forma esporádica o 
definitivamente evitarlo. Es interesante que considere que sus alumnos no son capaces de trabajar autónomamente:

\section{Citas Textuales}

- No voy a trabajar, lo voy hacer tradicional porque finalmente, es un stress porque tienes, en este caso son, eran 30 alumnos en la sala, creo que la mayoría de las veces estuvo el curso completo, 30 alumnos a los cuales tienes que ir uno por uno indicándoles cómo hacer el paso, que una suma, uno esquiva el trabajo con las TIC

Ahora cuando utiliza la tecnología dirige el accionar de sus alumnos, esto siempre congruente con el modelo Transmisionista/Reproductivo, esto que da claro en las siguientes citas.

\section{Citas Textuales}

- Hay una plataforma, yo puedo subir documentos, puedo mandarle información.

- ...tú les dices a esta página, con este trabajo.

- ..... yo así evito que ellos vayan, no sé pos, a muchas páginas

- ... siendo que estaba en cada uno de los computadores (las páginas).

\subsection{CASO 2}

\section{a) Análisis tabla de frecuencia caso 2}

A diferencia del caso uno y del tres que sólo tienen cuatro, tiene cinco documentos primarios. Esta diferencia se da básicamente porque a la docente le tomó mayor tiempo terminar la unidad didáctica planificada. Los documentos primarios en este caso son: La entrevista semiestructurada, tres registros audiovisuales y la reflexión final. Estos documentos primarios analizados fueron codificados y se obtuvo la siguiente tabla de frecuencias:

\section{Tabla 4}

Distribución de Frecuencias de Documentos Primarios Caso 2

\begin{tabular}{|c|c|c|c|c|c|c|}
\hline Códigos & Entrevista & Filmación 1 & Filmación 2 & Filmación 3 & Reflexión & Total \\
\hline i2 & 2 & 2 & 0 & 1 & 0 & 5 \\
\hline i4 & 1 & 0 & 0 & 0 & 0 & 1 \\
\hline i5 & 1 & 0 & 0 & 0 & 0 & 1 \\
\hline i6 & 1 & 0 & 0 & 0 & 0 & 1 \\
\hline i7 & 0 & 0 & 0 & 0 & 1 & 1 \\
\hline i8 & 0 & 1 & 0 & 0 & 0 & 1 \\
\hline
\end{tabular}




\begin{tabular}{|c|c|c|c|c|c|c|}
\hline Códigos & Entrevista & Filmación 1 & Filmación 2 & Filmación 3 & Reflexión & Total \\
\hline i9 & 3 & 0 & 0 & 0 & 0 & 3 \\
\hline i10 & 0 & 1 & 0 & 1 & 1 & 3 \\
\hline i11 & 0 & 2 & 0 & 0 & 1 & 3 \\
\hline a1 & 1 & 4 & 6 & 10 & 2 & 23 \\
\hline a2 & 2 & 2 & 2 & 2 & 6 & 14 \\
\hline a3 & 3 & 1 & 0 & 0 & 3 & 7 \\
\hline a4 & 2 & 0 & 0 & 0 & 3 & 5 \\
\hline a5 & 4 & 1 & 1 & 0 & 0 & 6 \\
\hline a6 & 2 & 0 & 1 & 2 & 3 & 8 \\
\hline a7 & 0 & 3 & 1 & 2 & 0 & 6 \\
\hline a8 & 3 & 1 & 0 & 1 & 3 & 8 \\
\hline a9 & 2 & 1 & 0 & 1 & 1 & 5 \\
\hline a10 & 0 & 1 & 5 & 1 & 4 & 11 \\
\hline a11 & 0 & 0 & 7 & 3 & 0 & 10 \\
\hline a12 & 0 & 0 & 0 & 0 & 4 & 4 \\
\hline a13 & 0 & 5 & 1 & 2 & 3 & 11 \\
\hline a14 & 0 & 10 & 6 & 11 & 0 & 27 \\
\hline Totales & $\mathbf{2 7}$ & $\mathbf{3 5}$ & $\mathbf{3 0}$ & $\mathbf{3 7}$ & $\mathbf{3 5}$ & $\mathbf{1 6 4}$ \\
\hline
\end{tabular}

En una visión general la tabla 4 muestra que la totalidad de los códigos anclados en diversas dimensiones de la matriz alcanza una frecuencia de 164, siendo la más alta de los tres casos de este estudio. De este total, la categoría de mayor frecuencia corresponde al código a14, que tiene relación con la dimensión: Interacciones ante la computadora, en este caso las interacciones son complejas, alumno-alumno, alumnoprofesor, profesor-ordenador, alumno-ordenador, y podemos encontrarlas sólo en la observación de los registros audiovisuales digitalizados de la profesora. Por tanto, el código sólo está presente en tres de los documentos primarios, donde se evidencia su práctica pedagógica con el uso de TIC.

La segunda recurrencia con 23 la encontramos en el código al, el cual corresponde a la dimensión rol del profesor, caracterizado como guía-orientador; destaca del análisis que estos códigos sí se encuentran en todos los documento, primarios, siempre teniendo en cuenta que esta maestra tiene un documento primario más, es decir, una filmación más.

Así también, podemos encontrar una recurrencia de 14 en la dimensión rol del discente en la categoría Proactivos y autónomo código a2. Esto es consistente con lo que plantea Hernández Cardona (2002), acerca de cómo debiera ser un profesor de Historia para fomentar la participación crítica y activa del alumnado. 
Esta profesora sólo presenta códigos en dos categorías, en su caso sería Interaccionista/Constructiva y Abierta/Autónoma. Mas su mayor recurrencia está en los códigos que describen la categoría Abierta/Autónoma, son 145 de los 164 que se pudieron anclar en todos los documentos primarios. Lo cual también nos podría hablar de una profesora preferentemente abierta/autónoma, insistimos en el concepto preferentemente pues hay códigos de otra categoría. En esto seguimos a Brown (2003) y su definición de concepciones, como una estructura general mental, no uniforme ni simple. Por ende se entiende que ser parte de una categoría en términos absolutos es muy difícil.

Los otros códigos que pueden ser analizados por su frecuencia se adscriben a la dimensión: Racionalidad en el uso de TIC, la profesora se adscribe al código: catalizadora, a10, con un recurrencia de 11 . Su racionalidad tiene que ver con que la tecnología sea una fuente que va a producir el cambio en sus estudiantes. El segundo con la misma recurrencia, 11, se adscribe a la dimensión: El tipo de software que utilizan según los temas del plan de estudio, el código al que ella se adscribe es: Software de productividad, software cerrados y abiertos, enciclopedias y búsqueda en web, todas las potenciales herramientas de Internet, a13. Esto puede servir como un elemento de discusión pues claramente el caso 2 utiliza las tecnologías de manera diferente, pero también es la única que cursó un magíster en informática educativa, por tanto podría eventualmente tener mejor manejo de los recursos que las TIC ofrecen como posibilidades.

En cuanto a su interacción con las TIC, los anclajes en las cinco dimensiones que nos hablan de ellas son significativas, 69. Lo que sugiere la importancia que les asigna la docente a ellas, tanto en su discurso como en su práctica pedagógica.

b) Análisis mapa axial caso 2

Figura 2

Mapa axial caso 2

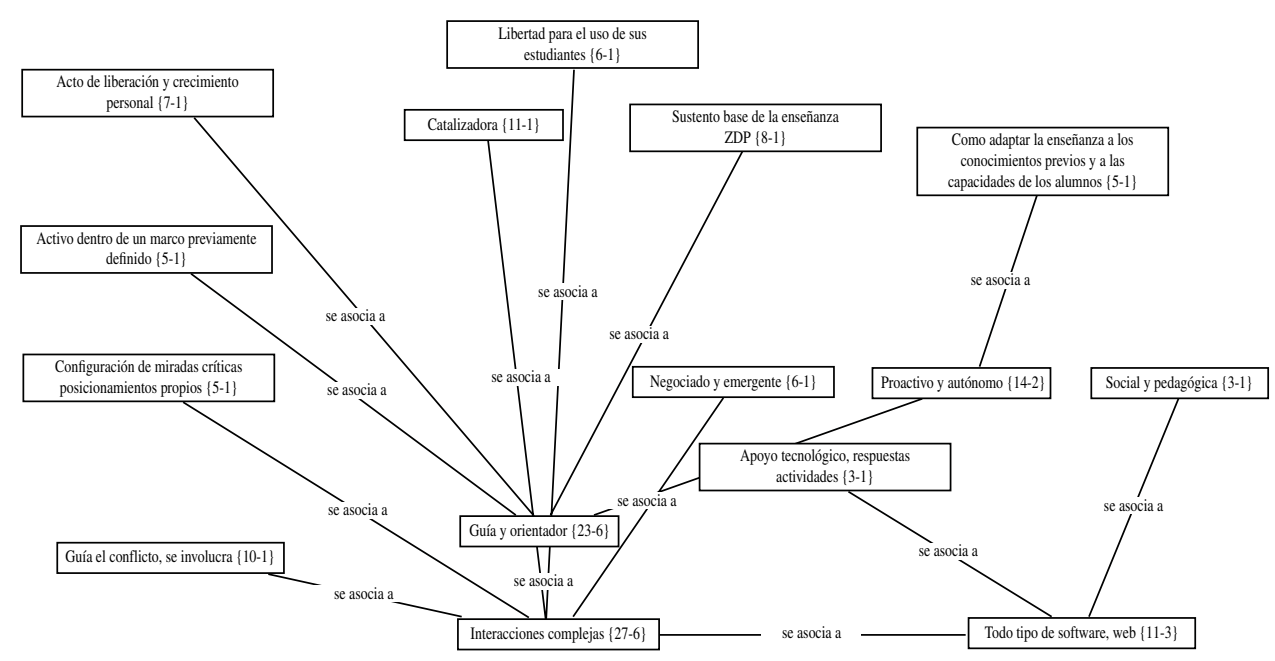


El mapa axial del caso 2 nos muestra el anclaje desde el código t14, que nos habla de la dimensión interacciones ante la computadora; en el caso de la profesora, presenta un interacción compleja, pues se provocan y producen múltiples vías de interacción a partir del trabajo en aula con TIC. Esto está en relación directa entre el tipo de categoría de profesora que es la docente preferentemente Abierta/Autónoma, por tanto su axial se ancla en esos códigos. También el análisis nos permite observar que este código posee una densidad relacional (27-6), con seis asociaciones. Se relaciona con los códigos: Guía el conflicto cognitivo, se involucra en las actividades como uno más al1; Catalizadora a10; Todo tipo de software. Software de productividad, software cerrados y abierto, enciclopedias y búsqueda de Web, todas las potencialidades de Internet al3. En un siguiente nivel de análisis el código de la dimensión rol de la profesora también alcanza un densidad relacional de seis, asociado con: Activo dentro de un marco previamente definido i2, Acto de liberación y crecimiento personal a3, libertad para el uso de sus estudiantes a7, Proactivo y autónomo a2, y Sustento base de la enseñanza (ZDP) a6. De estos códigos todos, menos uno, alcanzan densidad relacional de uno, con excepción del asociado a la dimensión: Formación continua y actualización con el código: Cómo adaptar la enseñanza a los conocimientos y las capacidades de los alumnos a4, esto está dado ya por un tercer nivel de análisis. Es importante recalcar que el axial del caso 2 logra abrirse a un nivel mayor de co-ocurrencia, eventualmente esto puede ser explicado por la cantidad de códigos anclados en la categoría. El caso presenta un mapa axial de mayores co-ocurrencias, y quizás esto nos permite caracterizar de mejor manera a la maestra. Por último, no parece significativo agregar que la docente si bien muestra rasgo de categoría interaccionista/constructivo es dado su análisis una profesora preferentemente adscrita a la categoría Abierta/Autónoma.

\section{Eventos significativos del discurso caso 2}

A partir del análisis tanto de la tabla de recurrencia como del mapa axial, hemos identificado a la profesora dentro de la categoría preferentemente Abierta/Autónoma. En su discurso, la profesora plantea elementos propios de la categoría, abierta donde lo fundamental es que el estudiante encuentre su camino al aprendizaje, ella sólo actúa como una guía dentro de esta ruta. Su práctica dentro de este modelo puede ser constatada a partir de las siguientes declaraciones:

\section{Citas Textuales}

- pero creo que es fundamental que los chiquillos aprendan haciendo.

- hay mucho interés de que los chiquillos participen y de alguna manera ellos hacen la clase, el rol mío es de síntesis y de hacer el nexo; creo que los que van construyendo son ellos

Ella busca que sus estudiantes asuman desafíos, los enfrenten y salgan airosos de ellos. En contexto abierto ella orienta, incluso hace la síntesis final, pero son sus alumnos quienes hacen la clase, ellos construyen sus aprendizajes.

En cuanto a la contextualización de aprendizajes, el sustento base de la enseñanza es referido al trabajo en la construcción de la zona de desarrollo próximo: 


\section{Citas Textuales}

- Para mí es fundamental que cada actividad, cada proceso que se encuentran, cada procedimiento que encuentran ellos sepan por qué y para qué lo están haciendo y que, incluso, revisen otro sentido no necesariamente lo que yo busco, a veces, ellos, incluso le encuentran otro sentido que no había pensado.

- Yo creo que cada uno y cada una de las estudiantes precisamente van construyendo; van interpretando y esas construcciones y esas interpretaciones de entender las cosas, evidentemente, se van complementando con las formas que tienen de entender el mundo; de entender cualquier fenómeno...

En cuanto al rol de sus estudiantes, estos se mueven dentro de un marco proactivo y autónomo, son ellos los que son el motor de su aprendizaje, y la docente en ese sentido respeta sus tiempos y sus formas de aprender.

\section{Citas Textuales}

- pero fue construyendo, aprendizajes de hecho yo las dejé bastante más solas precisamente por el grado de autonomía que ellas logran y bueno porque ellas trabajan bastante bien solitas.

- tienen bastantes habilidades de investigación, pero ellas van construyendo el aprendizaje o el conocimiento, van construyendo un conocimiento nuevo a partir de una pregunta básica, había una pregunta y para esa pregunta había que construir una respuesta.

- Hay una intención de que los estudiantes se enfrenten al conocimiento revisándose un poquitito respecto a lo que saben.

Para concluir, analizaremos la interacción de esta categoría de profesora con las TIC, donde su uso es también congruente con la categoría que se adscribe principalmente. Las considera relevantes para su relación con el contexto en el que sus alumnos se desarrollan, por ende para ella utilizar TIC se vuelve un elemento fundamental, donde para la motivación de sus estudiantes juega un rol preponderante. El rol de las TIC, siguiendo a Drenoyianni y Selwood (1998), es catalizador, y en su caso su uso está definido por una orientación para la transformación de las prácticas de enseñanza, la innovación se vuelve fundamental.

\section{Citas Textuales}

- yo creo que es fundamental (el uso de los computadores)

- ahora, desde el punto de la motivación ante un concepto de evaluación diagnóstica, yo creo que es irreemplazable.

- voy a incorporar un nuevo rol de las TIC, yo creo que en este mundo, en el contexto que vivimos, en el contexto de la imagen, el contexto del chat, de que esta herramienta en el fondo es casi un elemento fetiche, yo creo que hay muchos niños que están desmotivados con el tema de aprendizaje, yo creo que la tecnología es un rol apoyador.

Como el uso de las TIC para la profesora es fundamental, ya que considera que les abre espacios y puertas a sus estudiantes, por tanto utiliza todo lo que la tecnología le ofrece: todo tipo de software, internet abierta, blog, etc. Las citas que avalan esta afirmación son: 


\section{Citas Textuales}

- .....después, cuando se terminó la grabación, me preguntó la profesora cómo se hacen los blogs, enséñeme a hacer un blog y bueno nos quedamos un poco más de tiempo y aprendió inmediatamente, fue sumamente rápido con el tema de la tecnología a nivel pública en el blog.

- $\quad$........en el Word parece la idea era hacerla con el smart draw pero finalmente no se pudo poner en todos los computadores, fue super complicado porque si lo ponías se descargaba, se caía solo y bueno las chiquillas que tenían en su casa el smart draw después se fueron para la casa y tenían, está cargado en el blog con esa herramienta.....

En síntesis, y ante la evidencia la profesora presenta consistencia entre su discurso y el despliegue en el aula, con todo se la puede adscribir a la tercera categoría de la matriz, ella sería una maestra Abierta/Autónoma.

\subsection{CASO 3}

a) Análisis tabla de frecuencia caso 3

El caso 3 cuenta con cuatro documentos primarios, la entrevista semiestructurada, dos registros audiovisuales y la reflexión final. De estos documentos primarios se obtuvo la siguiente tabla de frecuencias:

\section{Tabla 5}

Distribución de Frecuencias de Documentos Primarios Caso 3

\begin{tabular}{|l|c|c|c|c|c|}
\hline Códigos & Entrevista & Filmación 1 & Filmación 2 & Reflexión & Total \\
\hline $\mathrm{t} 1$ & 2 & 0 & 1 & 1 & 4 \\
\hline $\mathrm{t} 2$ & 0 & 1 & 0 & 5 & 6 \\
\hline $\mathrm{t} 3$ & 2 & 1 & 0 & 0 & 3 \\
\hline $\mathrm{t} 4$ & 1 & 0 & 0 & 0 & 1 \\
\hline $\mathrm{t} 5$ & 2 & 1 & 0 & 1 & 4 \\
\hline $\mathrm{t} 6$ & 1 & 2 & 0 & 1 & 4 \\
\hline $\mathrm{t} 8$ & 2 & 0 & 0 & 3 & 5 \\
\hline $\mathrm{t} 11$ & 0 & 0 & 0 & 2 & 2 \\
\hline $\mathrm{i} 1$ & 0 & 1 & 1 & 0 & 2 \\
\hline $\mathrm{i} 2$ & 0 & 2 & 1 & 2 & 5 \\
\hline $\mathrm{i} 3$ & 1 & 0 & 0 & 0 & 1 \\
\hline $\mathrm{i} 5$ & 2 & 0 & 0 & 0 & 2 \\
\hline $\mathrm{i} 7$ & 0 & 0 & 0 & 3 & 3 \\
\hline $\mathrm{i} 8$ & 1 & 0 & 0 & 2 & 3 \\
\hline
\end{tabular}




\begin{tabular}{|l|c|c|c|c|c|}
\hline Códigos & Entrevista & Filmación 1 & Filmación 2 & Reflexión & Total \\
\hline i9 & 2 & 0 & 0 & 0 & 2 \\
\hline i10 & 2 & 2 & 0 & 5 & 9 \\
\hline i11 & 0 & 3 & 1 & 5 & 9 \\
\hline i12 & 0 & 0 & 0 & 5 & 6 \\
\hline i13 & 2 & 0 & 1 & 1 & 4 \\
\hline i14 & 0 & 0 & 1 & 0 & 1 \\
\hline a11 & 0 & 4 & 0 & 0 & 4 \\
\hline a13 & 0 & 1 & 0 & 0 & 1 \\
\hline a14 & 0 & 0 & 4 & 0 & 4 \\
\hline Totales & $\mathbf{2 1}$ & $\mathbf{1 8}$ & $\mathbf{1 0}$ & $\mathbf{3 6}$ & $\mathbf{8 5}$ \\
\hline
\end{tabular}

En una visión general la tabla 5 muestra que la totalidad de los códigos anclados en diversas dimensiones de la matriz alcanzan una frecuencia de 85. De este total encontramos los tres códigos, esto quiere decir que las tres categorías están representadas en los diferentes documentos primarios de la profesora. La mayor recurrencia corresponde a los códigos i, categoría Interaccionista/Constructiva con un anclaje de 46. Luego encontramos los códigos t correspondientes a la categoría Transmisionista/Reproductiva con un anclaje de 29. Por último, hay presencia de códigos que caracterizan a la categoría Abierta/Autónoma con 10.

Los dos anclajes de mayor frecuencia que son códigos $i$ y $t$ están presentes en todos los documentos primarios de la docente, por tanto, en su práctica y discurso. En cambio, los códigos $a$ sólo se manifiestan en las filmaciones digitalizadas, lo que quiere decir que los muestra tan sólo en su práctica pedagógica. Entonces nos encontramos con una profesora que se mueve en dos categorías con mayor presencia, pero también con presencia de acciones docentes adscritas en la tercera categoría.

En este caso encontramos la mayor dispersión en relación a los otros dos casos. Eventualmente, esta distribución hace más difícil identificar a la profesora con una de las tres categorías descritas en el marco teórico. Siguiendo sólo un criterio numérico que es el de mayor frecuencia, es plausible afirmar que la docente se enmarca preferentemente como Trasmisionista/Reproductiva. Sin embargo, como veremos más adelante, ha sido difícil adscribirla preferentemente a una de las categorías, y bajo esta premisa haremos el análisis.

En este caso encontramos dos dimensiones que tienen las mayores frecuencias: Racionalidad en el uso de las TIC y Tipo de ayuda que ofrece a sus estudiantes. En la primera dimensión el anclaje es de 9 en el código: Social y Pedagógica i10. Así también, encontramos un anclaje de 9 en el código i11: Apoyo tecnológico y respuestas sobre las actividades. Ambas frecuencias se dan sólo en tres de los cuatro documentos primarios.

En cuanto al uso de las TIC la profesora, la maestra, se mueve dentro de las categorías Interaccionista/Constructiva y Abierta/Autónoma. Lo cual no lleva a reforzar la idea que no es posible adscribirla a una categoría, esto consecuente con el tema de que las concepciones no son absolutas. 
b) Análisis mapa axial caso 3

Fifura 3

Mapa axial caso 3

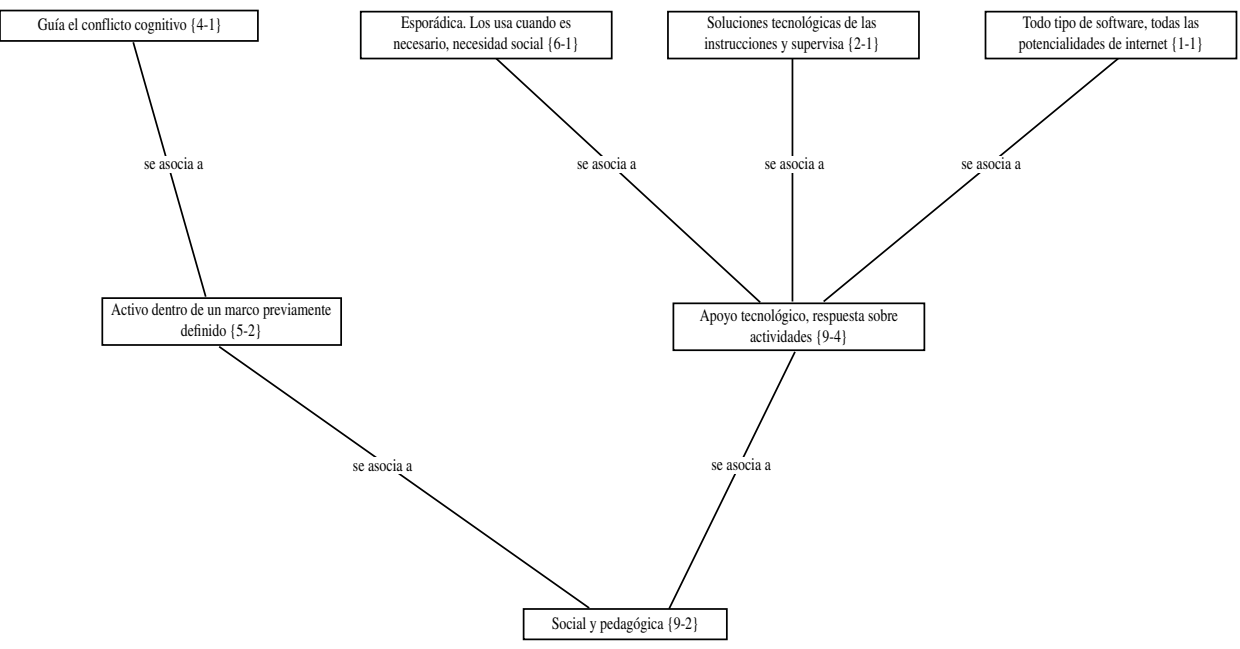

El caso 3 presenta dos códigos de igual anclaje: social y pedagógico ilo y Apoyo tecnológico y respuestas sobre las actividades. Deja que sus alumnos trabajen ill. El análisis también nos permite observar qué código social y pedagógico alcanza una densidad relacional (9-2), con dos asociaciones, los códigos con los cuales se relacionan son: Apoyo tecnológico y respuestas sobre las actividades. Deja que sus alumnos trabajen ill y Activo dentro de un marco previamente definido i2. Este último código se relaciona con guía el conflicto cognitivo a11. La densidad relacional de Apoyo tecnológico y respuestas sobre las actividades. Deja que sus alumnos trabajen ill es de (9-4), y sus códigos asociados están en las tres categorías: Esporádica. Las usa cuando es necesario, necesidad social i12, Soluciones tecnológicas 111 y por último: Todo tipo de software a 13 .

El mapa axial de la profesora refuerza la idea que tanto en su discurso como en su práctica muestra dispersión, lo que hace complicado ponerla dentro de una categoría.

\section{c) Eventos significativos del discurso caso 3}

Del análisis realizado podemos decir que la profesora tiene códigos en todas las categorías, y el análisis discursivo se hará para reforzar la idea de que no predomina ninguna de las categorías.

En cuanto a su práctica, podemos decir que ser expositora es algo que está presente en su accionar, esto queda de manifiesto en:

\section{Citas Textuales}

- ....uno le explica, ellos refuerzan el contenido

- uno tiene responsabilidad también en la forma de mostrar los conocimientos, 
Pero también le interesa actuar como tutora de sus alumnos, esto se expresa en:

\section{Citas Textuales}

- ...a ver déjelo ahí un poquito, qué opinan ustedes, qué les parece....

Respecto a la contextualización de los aprendizajes ella se mueve dentro de la categoría Transmisionista, el tema de la ejemplificación del contenido es primordial:

\section{Citas Textuales}

- en cambio, la Revolución Francesa es algo, no es más actual, pero es más tangible... Algo de lo que ellos han oído hablar más. Igual pueden los cambios sociales de la Revolución Francesa, pero cuando tú les colocas el tema macro para ellos es más fácil... Por la experiencia que yo he tenido, no sé si siempre es así. Pero es más fácil para ellos, no sé si digerirlo, pero o poder desarrollarlo...

- Porque con esos conceptos vamos a trabajar, trabajamos durante toda la unidad y después lo vamos a ver más adelante también porque la historia universal de alguna forma igual se va entregando, entonces de alguna forma igual vamos a llegar a lo mismo y para que ellos también a partir de eso después puedan ejemplificar

El rol de sus estudiantes siempre es activo, pero moviéndose dentro de los parámetros dados, esto se puede apreciar en su discurso en las siguientes citas:

\section{Citas Textuales}

- ellos tenían que buscar información y que igual lo hicieron bastante bien porque trabajaron los que debían trabajar.

- creo dentro de lo que ellos pueden hacer, o sea, lo ideal hubiera sido más participación porque no es que uno le muestra las imágenes y lo ideal es que ellos vayan levantando la mano, vayan preguntando o vayan acotando.

También el rol de discente desde la óptica de una profesora transmisionista, donde su rol es más bien pasivo siguiendo instrucciones haciendo lo que se le pide, esto ve en las siguientes citas:

\section{Citas Textuales}

- Aunque igual es un poco monótono, porque me refiero a que todos los alumnos hacen su exposición y en este caso en vez de exponer leen, por eso que lo ideal es que el alumno exponga lo que entiende.

- Cada vez que uno le pregunta por las instrucciones de lo que sea, lo pregunta en el momento pero antes, cuando tú les das la instrucción.

Para terminar el análisis de las citas textuales nos referiremos a la utilización que hacen de las TIC, nos parece importante consignar que la profesora dentro de su formación inicial tuvo seis semestres de informática educativa. Su accionar con las tecnologías se demuestra a través de las siguientes citas: 


\section{Citas Textuales}

- tiene que ver con un tema de recurso: los recursos se están usando a cabalidad, pero si hubiera dos salas de informática sería mejor...

- yo me pongo en el caso si tengo acá una pizarra (digital) o sea igual tiene que tener una capacitación aparte de lo que uno ya sabe para tener una interacción con los alumnos respecto del instrumento.

- $\quad$ siempre está llena (la sala de computación), está todo el día llena porque le toca un curso porque le toca a otro.

Su uso de software o internet es variado y lo declara de la siguiente manera:

\section{Citas Textuales}

- Para buscar conceptos, que siempre se hace al principio de la unidad... Investigación de temas específicos, presentaciones y en Word también, que es lo que más se trabaja.

- Entonces ellos también tienen que saber discriminar la información y tratar de no buscar en una sola dirección porque en algunas, por ejemplo, salen cosas, no sé po, tienen varias alternativas tienen que buscar información más adecuada.

Trabaja con la búsqueda de web, y también con software de productividad cerrada como el Word, y como se vio en su mapa axial, cree que las TIC cumplen una función social pero también son para ella una poderosa herramienta pedagógica.

Para terminar, se puede afirmar que la profesora es la que presenta la mayor dispersión, por tanto no se la va a adscribir a ninguna categoría, tanto en su práctica como en su discurso se movió dentro de las tres categorías.

\subsection{SINTESIS COMPARATIVA DE CASOS}

Siguiendo con el análisis intracasos, nos enfocaremos en los análisis realizados de las tablas de frecuencia, los mapas axiales y los datos textuales. En estos aspectos hay elementos diferenciadores, que nos hablan de distintas concepciones sobre enseñar y aprender y que configuran formas diversas de aproximarse al uso de las TIC.

De los tres casos estudiados llama la atención que si se consideran las frecuencias estas son diversas: caso 1: 115, caso 2: 164, caso 3: 85. Hemos establecido que las dos primeras profesoras se adscriben a las categorías Transmisionista/Reproductiva y la segunda Abierta/Autónoma, y el tercer caso se nos presentó con dispersión dentro de las tres categorías. Es significante que ninguna profesora manifiesta una presencia absolutamente pura de códigos en una sola categoría, y siguiendo a Brown (2003), las concepciones como una estructura de mente no son uniformes ni simples. Por tanto, se entendería que todas nuestras maestras mostraran rasgos en el discurso y en la acción de las tres categorías definidas teóricamente.

En cuanto a las convergencias de nuestras profesoras, recurriendo a sus tablas de frecuencias, es posible observar que las tres utilizan en algún momento de su discurso o de su práctica un uso de las TIC con una racionalidad carácter social y pedagógico (Drenoyianni y Selwood, 1998). 
En cuanto a los mapas axiales cada una, tal cual como preveíamos, produjo un mapa axial propio y diferenciado de los otros, lo que refleja que cada una configura su concepción a partir de dimensiones prioritarias, o mejor dicho más recurrentes (mayor anclaje) en su discurso y acción.

En cuanto a los datos textuales es difícil establecer una comparación intercasos, cuestión que se sustenta en que pese a que son sólo tres casos, la diversidad es una constante, diversos sus contextos, sus experiencias, por tanto sus concepciones y vivencias asociadas, es decir, éstas se vinculan a sus propias representaciones cognitivas y sus creencias (Da Ponte, 1999).

Las convergencias de nuestras profesoras permiten observar que las tres utilizan las TIC en algún momento de su discurso o de su práctica con un carácter social y pedagógico, lo que en cierta medida permite aseverar que existe al menos declarado o manifiesto una intención de utilizar TIC no sólo por la demanda social sino también por el apoyo pedagógico que ofrece. Este hecho no es menor, debido a que al parecer cada vez se ha venido reduciendo la brecha generacional como una "escusa" para no usar la TIC. Este es un elemento para la discusión, puesto que las redes sociales digitales (web 2.0) se han vuelto tan utilizadas en nuestro país, que se presentan sin duda como un elemento de apoyo a la enseñanza y aprendizaje de los estudiantes de enseñanza media.

\section{CONCLUSIONES}

Los resultados de esta investigación evidenciaron que las categorías construidas teóricamente (Transmisionista/Reproductiva, Interaccionista/Constructiva y Abierta/Autónoma) permitieron caracterizar de manera adecuada las concepciones sobre el uso educativo de las TIC en profesores de Historia. Lo que se reflejó en una profesora Transmisionista/ Reproductiva, otra Abierta/Autónoma y una tercera que se movió de manera similar entre Transmisionista/Reproductiva e Interaccionista/Constructiva. Lo cierto es que esta construcción categorial en tres ejes permite ciertamente obtener una caracterización de las concepciones de los profesores sobre aprender y enseñar con TIC para luego relacionarlas con sus prácticas

En este último sentido dos de los tres casos manifestaron una consistente relación entre el discurso y la acción, puesto que sus entrevistas guardaron relación con lo que logramos analizar de sus videos de clases. En tanto en el tercer caso no se adscribe a una categoría determinada, y presenta códigos en todas las categorías, podría ser definida como multicategorial.

Así, en el artículo se han caracterizado las concepciones sobre aprender y enseñar con TIC de tres profesoras de Historia de Enseñanza Media de la comuna de Valdivia y su relación con las prácticas de aula en que usan TIC.

\section{BIBLIOGRAFIA}

Arancibia, M. (2002). Transformaciones en las organizaciones educativas que posibiliten aprendizajes transdisciplinarios con utilización de recursos informáticos. Estudios Pedagógicos 28 : $143-156$. 
Brown, G. (2003). Teachers' Instructional Conceptions: Assessment's relationship to learning, teaching, curriculum, and teacher efficacy. En: Joint Conference of the Australian and New Zealand Associations for Research in Education (AARE/NZARE) Auckland. Consultado en $<$ http://www.aare.edu.au/03pap/bro03022.pdf [última visita 12/02/2008].

Boulton-Lewis, G., D. J. Smith, A. R. McCrindle, P. C. Burnett, P. C. \& K. J. Campbell (2001). Secondary teachers' conceptions of teaching and learning. Learning and Instruction 11, 35-5.

Cabero, J. (1991). Análisis, selección y evolución de medios audiovisuales didácticos. Consultado en http://tecnologiaedu.us.es/nweb/htm/pdf/43.pdf [última visita 03/08/2008].

Castells, M. (2001). Globalización y Antiglobalización, Diario El País. Consultado en http://inicia. es/de/cgarciam/castells.htm [última visita 30/12/2007].

Castells, M. (1997). La Era de la Información. Volumen 1, La Sociedad Red. Madrid: Alianza Editorial.

Clark, M. y P. Peterson (1990): "Procesos de pensamiento de los docentes". En: Witrock, M. La investigación de la enseñanza. III. Paidós. Barcelona.

Colas, P. (2003). Internet y aprendizaje en la sociedad del conocimiento. Comunicar, marzo $\mathrm{N}^{\circ} 20$. Pp. 31-36, Barcelona.

Coll, C. (2005): “Concepciones y tendencias actuales en psicología de la Educación”. En: Coll, C.; Palacios, J. y A. Marchesi. Desarrollo Psicológico y Educación. 2. Psicología de la educación escolar (pp. 29-66). Madrid: Alianza.

Da Ponte, J. (1999). Las creencias y concepciones de maestros como un tema fundamental en formación de maestros. En: Krainer, K.; F. Goffree (eds.), On research in teacher education: From a study of teaching practices to issues in teacher education. Osnabrück: Forschungsintitut für Mathematikdidaktik. Pp. 43-50.

Drenoyianni, H. \& I. Selwood (1998). Conception or misconceptions? Primary teachers'perceptions and use of computers in the classroom. Education and information Technologies 3, 87-99.

Denzin, N. K.(1994). The Art and Politics of Interpretation en Denzin, N.K. \& Y.S. Lincoln (eds.), Handbook of Qualitative Research, Sage, Thousand Oaks, Calfornia.

Doménech, F. \& A. Gómez (2004). Trainee teachers' conceptions of teaching and learning, classroom layout and exam design. Educational Studies, 30 (4): 355-372.

Da Ponte, J. (1999). Las creencias y concepciones de maestros como un tema fundamental en formación de maestros. En: Krainer, K.; F. Goffree (eds.), On research in teacher education: From a study of teaching practices to issues in teacher education. Osnabrück: Forschungsintitut für Mathematikdidaktik (43-50).

Duart, J. y A. Sangrà. Comp. (2000). Aprender en la Virtualidad. Barcelona: Gedisa.

Esteve, J. (2003). La tercera revolución Educativa. Barcelona: Paidós.

Hargreaves, A. (2003). Enseñar en la Sociedad del Conocimiento. Barcelona: Octaedro.

Lefebvre y otros (2006). ICT implementation stages of primary school teachers: the practices and conceptions of teaching and learning. Papers presentado en Australian Association for Research in Educación Nacional Conference. Consultado en http://www.aare.edu.au/06pap/lef06578.pdf [última visita 12/02/2008].

Moradiellos, E. (1994). El oficio de historiador. Siglo XXI: Madrid.

Mumtaz, S. (2000). Factors Affecting Teachers' Use of Information and Communications Technology: a review of the literature. Journal of Information Technology for Teacher Education, Vol. 9, $\mathrm{N}^{\mathrm{o}}$ 3, 2000. University of Warwick, Coventry, United Kingdom.

Niederhauser, D. \& T. Stoddart (2001). Teachers' instrucctional perspectivas and use of educational software. Teaching \& Teacher Education, 17 (1): 15-31.

Pecharromán, I. y J. Pozo (2006): “¿Qué es el conocimiento y cómo se adquiere? Epistemológicas intuitivas en profesores y alumnos". En: Pozo, J. y otros: Nuevas formas de pensar la Enseñanza y el aprendizaje. Las concepciones de profesores y alumnos. Barcelona: Grao. 
Pozo, J. y otros (2006). Nuevas Formas de Pensar la Enseñanza y el Aprendizaje. Barcelona, España. Colección Crítica y Fundamentos.

Pratt, D. (1992). Conceptions of Teaching. Adult Education Quarterly, 42 (4): 203-220.

Reggini, H. C. (1988): Computadoras: ¿creatividad o automatismo? Buenos. Aires: Kapelusz.

Ruiz OIabuénaga, J. (1999). Metodología de la Investigación Cualitativa. Bilbao, España: Universidad de Deusto.

Ruthven, K., S. Hennessy \& S. Brindley (2004). Teacher representations of the successful use of computer-based tools and resources in secondary-school English. Mathematics and Science Teaching \& Teacher Education, 20 (3): 259-275.

Sandín, P. (2003). Investigación cualitativa en educación. Barcelona: McGraw-Hill.

Snyder, I. (Comp.) (2004). Alfabetismos Digitales. Comunicación, Innovación y Educación en la Era Electrónica. Málaga: Ediciones Aljibe.

Stake, R. (1999). Investigación con estudios de casos. Madrid, España: Ediciones Morata.

Strauss, A. y J. Corbin (2002). Bases de la investigación cualitativa. Técnicas y procedimientos para desarrollar teoría fundamentada. Antioquía, Colombia: Editorial Universidad de Antioquía.

Taylor, S. J. y R. Bodgan (2002). Introducción a los métodos cualitativos de investigación. Barcelona, España: Editorial Paidós.

Thompson, A. (1992). Teachers' beliefs and conceptions: a synthesis of the research. En Grows, D.A. (ed.), Handbook of Research on Mathematics Teaching and learning. New York: Mac Millan.

Vasilachis de Gialdino, I. (coord.) (2006). Estrategias de investigación cualitativa. Barcelona: Gedisa.

Zhao, Y. \& K. Frank (2006). The Social Life of Technology. Pedagogies: An international Journal, Volume 1, Issue 2, abril 2006, pp. 135-14. Consultado en http://www.informaworld.com/smpp/ content $\sim$ content $=\mathrm{a} 785829934 \sim \mathrm{db}=$ all [última visita 3/08/2008]. 
